\title{
INFLUÊNCIA DO ESTÁDIO DE MATURAÇÃO DA FLOR NA PRODUÇÃO DE SEMENTES DE PIMENTÃO COM POLINIZAÇÃO MANUAL ${ }^{(1)}$
}

\author{
MARIA CAROLINA GODOY ${ }^{(2)}$; AMANDA REGINA GODOY ${ }^{(2)}$; \\ ANTONIO ISMAEL INÁCIO CARDOSO ${ }^{(2)}$
}

\begin{abstract}
RESUMO
O objetivo deste experimento foi avaliar a produção de sementes de pimentão com polinização manual de flores em diferentes estádios de maturação. Foram cinco tratamentos: polinização manual no dia da emasculação, um, dois e três dias depois da emasculação, sempre com flores emasculadas um dia antes da antese, além da testemunha, com polinização natural. $\mathrm{O}$ delineamento experimental foi em blocos ao acaso, com seis repetições de dez plantas. Foi obtida maior produção (massa e número) de sementes, por fruto e por polinização, com polinizações realizadas um dia antes e no dia da antese, que não diferiram da polinização natural.
\end{abstract}

Palavras-chave: Capsicum annuนm L., antese, polinização manual.

\section{ABSTRACT \\ INFLUENCE OF FLOWER STAGE MATURATION IN SWEET PEPPER SEED YIELD}

The purpose of this experiment was to evaluate the influence of flower development stage on sweet pepper seed yield in manual pollination. The trial was set up in a randomized complete block design, with five treatments, six replications and ten plants/plot. The treatments were manual pollination soon after flower emasculation; manual pollination one, two and three days after emasculation (always with flower emasculation one day before anthesis) and a control (natural pollination). Higher seed yields (weight and number), per fruit and per pollination, were obtained with pollination either one day before anthesis or at anthesis, treatments that did not differ from natural pollination.

Key words: Capsicum annuиm L., anthesis, manual pollination.

(1) Recebido para publicação em 26 de agosto de 2004 e aceito em 23 de janeiro de 2006.

( $\left.{ }^{2}\right)$ Departamento de produção Vegetal, Setor de Horticultura, Faculdade de Ciências Agronômicas, Universidade Estadual Paulista, Caixa Postal 237, 18603-970 Botucatu (SP). 


\section{Introdução}

Na espécie Capsicum annuum L. as flores são hermafroditas e, geralmente, ocorre a autofecundação natural, porém alguma polinização cruzada pode ocorrer entre e dentro da mesma cultivar ou de duas espécies, feita, muitas vezes, por insetos. Murthy e Murthy (1962) relataram mais de $68 \%$ de polinização cruzada na Índia. Apesar da predominância da autofecundação natural, híbridos comerciais têm sido tradicionalmente desenvolvidos por hibridação de variedades nos últimos 15 anos e alcançado prestígio comercial (MALUF, 2001).

A macho esterilidade genética e a macho esterilidade citoplasmática são mecanismos estudados e usados para a produção de sementes híbridas, porém a utilização de emasculação e polinização manual em larga escala na produção de híbridos ainda predomina (SHIFRISS, 1995).

A produção de sementes híbridas em solanáceas envolve a polinização manual de flores da linhagem feminina com pólen extraído de flores da linhagem masculina (GEORGE, 1999). As flores na linha feminina são primeiramente emasculadas durante seu estádio de botão em preparação para a polinização manual. Esse processo envolve a remoção completa de suas anteras e é feito em uma operação separada antes da aplicação de pólen em seu estigma.

Em pimentão, CASALI et al. (1984) relataram que o estigma já está receptivo na fase de botão, na véspera da antese, e a receptividade é máxima no dia da abertura da flor, decaindo após esta época. Antes da deiscência do pólen, o estigma já está receptivo ao pólen de outras plantas (GEORGE, 1999), ou seja, antes que o pólen da mesma flor esteja completamente maduro (Marfutina, 1974). Segundo Marcelis e HOFMAN-EIJER (1997), a receptividade do estigma ocorre um dia antes da antese até dois dias depois, totalizando quatro dias. O óvulo, por outro lado, é fertilizado e obtêm-se frutos, se a polinização ocorrer durante a antese ou no dia precedente.

QuAgLiotTi (1979), revisando diversos aspectos sobre hibridação artificial em pimentão, destacou que o melhor momento para a emasculação dos estames é imediatamente antes da antese e que a polinização imediatamente depois da emasculação aumenta a produção de sementes.

Em tomate, SHAKYA e SCOTT (1983) constataram que para todos os genótipos usados no estudo, a produção de sementes por polinização manual foi menor, quando era realizada um dia antes da antese, do que aquelas realizadas depois da antese.
$\mathrm{Na}$ produção de sementes híbridas, diariamente é realizada a emasculação, geralmente à tarde, e no dia seguinte pela manhã é realizada a polinização manual. Considerando-se que as operações de emasculação e transferência do pólen são trabalhosas, é interessante que o processo possa ser realizado em grande escala e com a maior eficiência, ou seja, maior produção de sementes híbridas por planta e por polinização realizada. Se as flores emasculadas forem polinizadas no mesmo dia da emasculação, há uma economia de tempo e mão-de-obra; assim, como se várias flores emasculadas em diferentes dias puderem ser polinizadas no mesmo dia, sem que haja perda na produtividade e qualidade das sementes obtidas.

Tendo em vista esses aspectos, o objetivo deste experimento foi avaliar a produção de sementes de pimentão com polinização manual das flores em diferentes estádios de maturação.

\section{Material e Métodos}

O experimento foi desenvolvido na Fazenda Experimental Lageado, pertencente à Faculdade de Ciências Agronômicas (FCA) da Universidade Estadual Paulista (UNESP), Campus de Botucatu, sob ambiente protegido.

Foram cinco tratamentos: polinização manual no dia da emasculação, um, dois e três dias depois da emasculação (o que corresponde ao dia anterior à antese, no dia da antese, um e dois dias após a antese da flor), além da testemunha, com polinização natural. O delineamento experimental foi em blocos ao acaso, com seis repetições sendo cada parcela constituída de 10 plantas.

Para evitar que ocorresse polinização natural, nos tratamentos com polinização manual, as flores foram emasculadas um dia antes da antese e as flores não polinizadas foram eliminadas. Após a emasculação, as flores foram protegidas com um saquinho de papel que permaneceu protegendo-as mesmo depois de realizada a polinização manual, evitando a polinização por insetos. As flores foram emasculadas quando entraram no estádio de botão floral, de acordo com GEORGE (1999).

As mudas foram obtidas em bandejas de poliestireno expandido com 128 células, com semeadura em 21/11/2001 e transplantadas em 3/ $1 / 2002$. As plantas foram desbrotadas até o aparecimento da primeira flor.

A cultivar Magda foi utilizada tanto para extração de pólen como para a realização das polinizações. O espaçamento utilizado foi de $1,0 \times 0,5$ 
$\mathrm{m}$. As plantas receberam adubações quinzenais com MAP, nitrato de cálcio e nitrato de potássio (2 g/ planta de cada fertilizante).

As polinizações manuais foram efetuadas em várias flores de cada planta, mas foram deixados apenas dois frutos por planta, e na polinização natural foram deixados dois frutos por planta para avaliar-se o potencial de produção de sementes por fruto sem grande competição dentro da planta. A flor da primeira bifurcação não foi utilizada, tendo em vista que um fruto fixado nessa posição poderia prejudicar o desenvolvimento da planta e conseqüentemente o pegamento de novo fruto. As polinizações foram iniciadas em 9/2/2002 e estenderam-se até 27/2/2002.

A extração dos grãos de pólen foi feita de flores recém-abertas colhidas no dia anterior ao da polinização. As anteras eram removidas e colocadas em uma caixa de isopor fechada contendo cal virgem, para que toda a umidade fosse retirada, onde permaneciam por 24 horas. Depois de secas, as anteras eram friccionadas contra uma peneira para que os grãos de pólen fossem liberados. A polinização foi feita colocando-se uma quantidade de grãos de pólen em uma tampa de caneta, que servia como veículo para permitir que fossem encostados no estigma das flores emasculadas.

Os frutos foram colhidos quando mudavam da cor verde para a vermelha. As sementes foram retiradas e colocadas para secar em pratos de barro. Depois de secas, as sementes foram guardadas em câmara seca, até atingirem 14\% de umidade.

Foram avaliadas as seguintes características: porcentagem de pegamento de frutos, massa média de fruto, produção (massa e número) de sementes por fruto e a massa de mil sementes. Também foram obtidos os valores de produção de sementes por polinização manual multiplicando-se a produção de sementes (número e massa) por fruto pela porcentagem de pegamento, com o objetivo de se comparar a eficiência na produção de sementes em cada operação de polinização manual.

Foram realizadas análises de variância e as médias foram comparadas pelo teste de Tukey a 5\% de probabilidade.

\section{Resultado-s e Discussão}

Não houve diferença significativa entre os tratamentos com relação ao pegamento dos frutos (Tabela 1). Em média, cerca de $90 \%$ das flores polinizadas se desenvolveram em frutos. Apenas observou-se menor pegamento quando a polinização foi realizada três dias após a emasculação. Marcelis e Hofman-Eijer (1997) constataram que a receptividade do estigma ocorre um dia antes da antese e até dois dias depois, perfazendo o total de quatro dias. Entretanto, relataram que o óvulo é fertilizado e obtém-se frutos se a polinização ocorrer durante a antese ou no dia precedente. Já CASAli et al. (1984) relataram que o estigma do pimentão pode estar receptivo na fase de botão floral, na véspera da antese e duas a três horas após a abertura da flor. Para as condições deste experimento, o pegamento de frutos não foi reduzido significativamente, mesmo com polinizações realizadas dois dias após a antese.

Provavelmente, a porcentagem de pegamento não foi afetada nesse experimento pois em nenhum dos tratamentos observou-se quantidade de sementes por fruto menor que 100 (Tabela 2) e, segundo MARCELIS e Hofman-Eijer (1997), só há uma diminuição no pegamento de frutos em pimentão, quando o número de sementes for inferior a 100 por fruto. Deve-se destacar, também, que foram deixados apenas dois frutos por planta, evitando-se redução no pegamento por competição entre frutos. A primeira flor foi eliminada e somente as flores que sucederam a primeira foram utilizadas, o que também favoreceu o pegamento (Kato e TANAKa,1971; Nuez et al., 1996). Segundo Marcelis e Hofman-Eijer (1997) e Heuvelink e KÖRNER (2001), a inibição no pegamento de novos frutos pela presença de outros frutos em desenvolvimento decorre tanto pela competição por fotoassimilados como por dominância devido à produção de fitorreguladores.

Para a massa média de frutos não foram observadas grandes diferenças (Tabela 1), apenas quando as flores foram polinizadas três dias após a emasculação foram obtidos frutos com massa inferior à maioria dos tratamentos. Essa redução foi de aproximadamente $18 \%$ em relação aos frutos dos demais tratamentos, provavelmente por possuírem um número menor de sementes. MARCELIS e HofMAN-EIJER (1997) também observaram um aumento no tamanho do fruto com o aumento no número de sementes e que o número de sementes afeta mais a taxa de crescimento do que o período de crescimento dos frutos.

Destaca-se que foram obtidos frutos com a mesma massa nas polinizações manuais realizadas até dois dias após a emasculação em comparação à testemunha (polinização natural), mostrando que a polinização manual não afetou esta característica do fruto. 
Tabela 1. Médias da porcentagem de pegamento e de massa média de frutos. Botucatu, FCA-UNESP, 2002

\begin{tabular}{lccc}
\hline $\begin{array}{c}\text { Tratamento } \\
\text { (dias após a emasculação) }\end{array}$ & $\begin{array}{c}\text { Número de dias } \\
\text { da antese }\end{array}$ & Pegamento & Massa de fruto \\
\hline Polinização natural & - & - & 103,8 a \\
0 & -1 & 89,6 a & 107,9 a \\
1 & 0 & 94,2 a & 99,1 ab \\
2 & +1 & $90,1 \mathrm{a}$ & $82,8 \mathrm{~b}$ \\
3 & +2 & $80,3 \mathrm{a}$ & 10,85 \\
\hline C. V.(\%) & - & 5,38 & \\
\hline
\end{tabular}

Médias seguidas pela mesma letra, nas colunas, não diferem estatisticamente pelo teste de Tukey a 5\% de probabilidade.

Tabela 2. Médias de produção de sementes por fruto (PSF), massa de mil sementes (M1000) e produção de sementes por polinização (PSP). Botucatu, FCA-UNESP, 2002

\begin{tabular}{lcccccc}
\hline $\begin{array}{l}\text { Tratamento } \\
\text { (DAE) }\end{array}$ & $\begin{array}{c}\text { Número de dias } \\
\text { da antese }\end{array}$ & \multicolumn{2}{c}{ PSF } & M1000 & PSP \\
\hline & & $\mathrm{g}$ & $\mathrm{g} .^{\circ}$ & & $\mathrm{n} .^{\circ}$ \\
Pol. natural & - & $1,8 \mathrm{a}$ & $287,9 \mathrm{a}$ & $6,2 \mathrm{a}$ & - & - \\
0 & -1 & $1,5 \mathrm{ab}$ & $232,7 \mathrm{ab}$ & $6,4 \mathrm{a}$ & $1,40 \mathrm{ab}$ & $208,57 \mathrm{ab}$ \\
1 & 0 & $1,5 \mathrm{ab}$ & $249,6 \mathrm{ab}$ & $6,2 \mathrm{a}$ & $1,45 \mathrm{a}$ & $234,65 \mathrm{a}$ \\
2 & +1 & $1,3 \mathrm{~b}$ & $204,6 \mathrm{~b}$ & $6,4 \mathrm{a}$ & $1,16 \mathrm{~b}$ & $185,25 \mathrm{~b}$ \\
3 & +2 & $0,7 \mathrm{c}$ & $125,8 \mathrm{c}$ & $5,4 \mathrm{a}$ & $0,54 \mathrm{c}$ & $99,98 \mathrm{c}$ \\
\hline C.V. $(\%)$ & & 16,78 & 16,47 & 9,35 & 13,10 & 11,52 \\
\hline
\end{tabular}

Médias seguidas pela mesma letra, nas colunas, não diferem estatisticamente pelo teste de Tukey a 5\% de probabilidade.

DAE - dias após a emasculação.

A produção de sementes por fruto, em massa e número, foi maior nos frutos que tiveram a sua polinização natural (Tabela 2), embora não tenha havido diferença significativa em relação às polinizações manuais realizadas no dia da emasculação e um dia após (no dia da antese). Obtevese menor produção no tratamento com polinização manual realizada três dias após a emasculação.

Scott e George Jr. (1980) obtiveram maior quantidade de sementes com polinização um dia após a emasculação em tomate. Já SHAKYA e ScOTT (1983) observaram menor produção para a polinização no dia da emasculação. Em pimentão, QuAGLiotTi (1979) destacou que o momento ideal para polinizar uma flor é logo após a emasculação. Portanto, os resultados obtidos no presente trabalho são semelhantes à média dos resultados relatados na literatura para solanáceas.

Os valores obtidos para massa de sementes foram superiores aos relatados por SiLVA et al. (1971), que estudaram a cv. Ikeda com polinização natural, obtendo a média de 1,32 g de sementes por fruto. Para o número de sementes, porém, os valores foram inferiores ao relatado por MANTOVANI et al. (1980), com a cv. Avelar com polinização natural, que obtiveram a média de 367 sementes por fruto.

Para massa de mil sementes não se obteve diferença significativa entre os tratamentos. Entretanto, observou-se menor valor quando a polinização foi realizada três dias após a emasculação (Tabela 2). A massa de mil sementes pode ser considerada tanto uma característica de análise de produtividade como de qualidade de sementes. Primeiramente, porque possibilita averiguar o quanto pesa a semente, e segundo, sua densidade pode influir nos testes de vigor e germinação devido à quantidade de reserva energética (Vieira e Carvalho, 1994).

Para a produção, número e massa de sementes por polinização, o melhor tratamento foi a polinização realizada um dia após a emasculação (no dia da antese); na polinização realizada dois dias após a emasculação já se obteve produção menor na polinização manual e três dias após obteve-se a menor produção (Tabela 2). Essa avaliação de produção 
de sementes pode ser considerada mais interessante que a produção por fruto, pois reflete a relação "custo:benefício" dessa polinização manual, e indica o quanto o produtor vai obter de sementes para cada operação de polinização manual. Pode ser considerada uma síntese de eficiência, pois combina a taxa de pegamento de frutos e a produção de sementes por fruto. Nesse caso, tanto faz a polinização ser realizada logo após a emasculação ou no dia seguinte que foram os tratamentos com maior produção de sementes por polinização e que não diferiram da polinização natural na produção por fruto.

A redução na produção de sementes, por polinização manual realizada, foi de cerca de 50 sementes, com a polinização realizada um dia após a antese em comparação a realizada no dia da antese. Pode-se considerar esse valor uma redução altamente significativa tratando-se de produção de sementes híbridas que, geralmente, são vendidas em embalagens com mil unidades. Portanto, a cada 20 polinizações o produtor deixaria de produzir um envelope com mil sementes.

Portanto, na produção por polinização manual, observa-se que pode não ser economicamente viável o aproveitamento das flores que não puderam ser polinizadas no dia seguinte à emasculação, pois vão produzir menos sementes e iriam competir com as outras que viessem a ser polinizadas posteriormente. Geralmente, há uma redução no pegamento de frutos em pimentão quando a planta já tem grande número de frutos vingados (Nuez et al, 1996; MARCelis e HofMAN-EIJer, 1997).

\section{Conclusão}

Dentre os tratamentos com polinização manual, obteve-se maior produção de sementes com a polinização realizada logo após a emasculação e no dia seguinte (dia da antese), não diferindo da polinização natural.

\section{Agradecimentos}

Os autores agradecem à FAPESP pela concessão da bolsa de Iniciação Científica à primeira autora (Processo 00/06180-0) e auxílio à pesquisa (Processo 01/09762-3).

\section{Referências}

CASALI, V.W.D.; PÁDUA, J.G..; BRAZ, L.T. Melhoramento de pimentão e pimenta. Informe Agropecuário, Belo Horizonte, v.10, n.113, p.19-22, 1984.
GEORGE, R.A.T. Vegetable seed production. London: CABI Publishing, 2.ed. 1999. 219p.

HEUVELINK, E.; KÖRNER, O. Parthenocarpic fruit growth reduces yield fluctuation and blossom-end rot in sweet pepper. Annals of Botany, London, v.88, p.69-74, 2001.

KATO, T.; TANAKA, M. Studies on the fruit setting and development of sweet pepper. I. Fruiting behavior. Journal of Japanese Society for Horticultural Science, Kyoto, v.40, p.359-366, 1971.

MALUF, W. R. Heterose e emprego de híbridos F1 em hortaliças. In: NASS, L.L. et al. (Ed.) Recursos genéticos e melhoramento de plantas. Rondonópolis: Fundação MT, 2001. cap.13, p. 327-355.

MANTOVANI, E.C.; SILVA, R.F.; CASALI, V.W.D.; CONDÉ, A.R. Desenvolvimento e maturação fisiológica de sementes de pimentão (Capsicum annum L.). Revista Ceres, Viçosa, v.27, n.152, p.356-368, 1980.

MARFUTINA, V. P. Obtaining hybrid seeds of sweet pepper without emasculation of the flowers. Plant Breeding Abstracts, New York, v.10, p. 288, 1974.

MARCELIS, L. F. M.; HOFMAN-EIJER, L. R. B. Effects of seed number on competition and dominance among fruits in Capsicum annuum L. Annals of Botany, London, v.79, n.6, p.687693, 1997.

MURTHY, N. S. R.; MURTHY, B.S. Natural cross pollination in chilli. Andhra Agriculture Journal, Bapatla, v. 9, n. 3, p. 163-5, 1962.

NUEZ, F.; GIL ORTEGA, R.; COSTA, J. El cultivo de pimientos, chiles y ajies. Ediciones Mundi-Prensa, 1996.

QUAGLIOTTI, L. Floral biology of Capsicum and Solanum melongena. In: HAWKERS, J. G.; LESTER, R. N.; SKELDING, A. D. (Eds.) The Biology and Taxonomy of the Solanaceae. London: Academic Press, 1979. p. 399-419.

SCOTT, J.W.; GEORGE, W.L. JR. Influence of environment and flower maturity on hybrid seed production in Lycopersicon esculentum Mill. Euphytica, Dordrecht, v. 9, p. 135-144, 1980.

SHAKYA, S. M.; SCOTT, J. W. Influence of flower maturity and environment on hybrid and selfed seed production of several tomato genotypes. Journal of American Society for Horticultural Science, Alexandria, v. 108, n. 5, p. 875-878, 1983.

SHIFRISS, C. Male sterility in Capsicum. Capsicum and Eggplant Newsletter, v.14, p.11-25, 1995.

SILVA, R.F.; COUTO, F.A.A.; TIGCHELAAR, E.; OLIVEIRA, L.M. Efeito do espaçamento e níveis de adubação na produção de sementes de pimentão (Capsicum annuum L.). Experientiae, Viçosa, v. 11, n. 8, p. 297-317, 1971.

VIEIRA, R.D.; CARVALHO, N.M. Teste de vigor em sementes. Jaboticabal: FCAV/FUNEP, 164 p. 1994. 